Bond University

Research Repository

\title{
Transitioning to university: Coping styles as mediators between adaptive-maladaptive perfectionism and test anxiety
}

Vanstone, Daisy Mary; Hicks, Richard Edward

Published in:

Personality and Individual Differences

DOI:

10.1016/j.paid.2018.12.026

Licence:

CC BY-NC-ND

Link to output in Bond University research repository.

Recommended citation(APA):

Vanstone, D. M., \& Hicks, R. E. (2019). Transitioning to university: Coping styles as mediators between adaptive-maladaptive perfectionism and test anxiety. Personality and Individual Differences, 141, 68-75. https://doi.org/10.1016/j.paid.2018.12.026

\section{General rights}

Copyright and moral rights for the publications made accessible in the public portal are retained by the authors and/or other copyright owners and it is a condition of accessing publications that users recognise and abide by the legal requirements associated with these rights.

For more information, or if you believe that this document breaches copyright, please contact the Bond University research repository coordinator 
Transitioning to University: Coping Styles as Mediators between Adaptive-Maladaptive Perfectionism and Test Anxiety

$$
\text { Daisy Mary Vanstone }{ }^{\mathrm{ab}} \text { and Richard Edward Hicks }{ }^{\mathrm{ac}}
$$

${ }^{a}$ Faculty of Society and Design, Bond University, 14 University Dr, Robina, QLD, Australia ${ }^{b}$ Email address of corresponding author: dvanston@bond.edu.au

cEmail address of co-author: rhicks@,bond.edu.au 


\section{Highlights}

- Examined coping styles used as mediators between perfectionism and test anxiety

- Avoidant emotion-focused coping mediated adaptive perfectionism and test anxiety

- Avoidant emotion-focused coping mediated maladaptive perfectionism and test anxiety

- Test anxiety theory provided a sound theoretical basis for examining relationships 


\begin{abstract}
Test anxiety is an important issue in academic settings as it is related to high drop-out rates. Despite research highlighting the effects of test anxiety in students, few studies have examined mechanisms that explain the relationship between students' pre-dispositions and their experience of test anxiety. To shed light on how universities can support students during the first year of university, the current study used Spielberger and Vagg's (1995) transactional process model of test anxiety as a framework for examining whether multiple coping styles explain the relationships between adaptive/maladaptive perfectionism and test anxiety. Participants (148) were first year students from south-east Queensland universities. Participants completed the Depression Anxiety Stress Scale - 21, Almost Perfect Scale Revised, Brief COPE Inventory, Test Anxiety Inventory, Marlowe-Crowne Social Desirability Scale, and a demographic questionnaire. Findings indicated that adaptive/maladaptive perfectionism worked through avoidant emotion-focused coping to predict levels of test anxiety. Thus, students with adaptive perfectionism may experience less test anxiety as they use less avoidant emotion-focused coping whereas students with maladaptive perfectionism may experience more test anxiety as they use more avoidant emotion-focused coping.
\end{abstract}

Keywords: perfectionism; coping styles; avoidant emotion-focused coping; test anxiety 


\section{Introduction}

Adjusting to university life largely depends on students' abilities to adapt to a learning environment that requires greater autonomy in completing required coursework and preparing for exams (Brinkworth, McCann, Matthews, \& Nordström, 2009; Karabenick \& Zusho, 2015). For a considerable proportion of students, the pressure to perform well combined with the highly critical nature of examinations can result in excessive test anxiety, leading to attrition within the first year of study and burnout over the course of a degree (Abdollahi, Carlbring, Vaez, \& Ghahfarokhi, 2016; Hunt \& Eisenberg, 2010). Much of the literature investigating the reasons for the high prevalence of attrition in first year students has cited personality traits and coping mechanisms as well as transitional challenges (e.g., moving from home) that may increase attrition (Bassols et al., 2014; Zamira, 2016). With Australia's university dropout rate worsening since 2009 , it is important to investigate whether specific coping mechanisms explain the relationship between first year students who self-impose performance pressure (i.e., perfectionism) and test anxiety (Department of Education and Training, 2017).

A review of the literature revealed inconsistent findings regarding how coping mechanisms explain the relationship between perfectionistic traits and level of test anxiety (Arana \& Furlan, 2016; Larijani \& Besharat, 2010). Research has primarily focused on relationships between coping mechanisms and test anxiety in the general university population. By investigating the mechanisms that mediate the relationship between predisposition (personality traits) and level of test anxiety, this study sought to provide an avenue for intervention to reduce attrition rates during the first year of university. As this study was conducted within an Australian population, it is proposed that Australian universities could use the findings from this study to assist new undergraduate students to 
cope more effectively with test anxiety (Moate, Gnilka, West, \& Bruns, 2016; Regehr, Glancy, \& Pitts, 2013).

\subsection{Test Anxiety in University Students}

High test anxiety within a university population has been linked to feelings of burnout and increased drop-out rates, suggesting heightened test anxiety during university has adverse effects on wellbeing (Chae, 2015; Duty, Christian, Loftus, \& Zappi, 2016). Current conceptualisations of test anxiety are based on Spielberger and Vagg's (1995) transactional process model, which regarded test anxiety as the interaction between pre-disposition and appraisal of testing situations as stressful. Perfectionism, a personality trait, has a strong association with negative cognitive appraisal of situations and an increased propensity for experiencing negative emotions (Castro, Soares, Pereira, \& Macedo, 2017; Wu et al., 2017). Weiner and Carton (2012) found that individuals with perfectionism who are concerned about social evaluation experience higher levels of test anxiety compared to individuals without this trait. This framework is important for understanding how personality factors such as perfectionism influence individuals' perceptions of testing situations, creating increased test anxiety.

\subsection{Types of Perfectionism and Levels of Test Anxiety}

Distinguishing between positive and negative aspects of perfectionism is important for understanding how these constructs are related to test anxiety. Hamachek (1978) postulated that individuals with maladaptive perfectionism (Discrepancy) are concerned about making mistakes, sensitive to criticism, and tend to ruminate about events. Numerous studies have supported this proposal and shown that maladaptive perfectionism may act as a transdiagnostic factor showing significant relationships with poor mental health outcomes including a high prevalence of anxiety (DiBartolo, Li, \& Frost, 2008) and low self-esteem (Moroz \& Dunkley, 2015). Hamachek (1978) also postulated that individuals with adaptive 
perfectionism (High Standards) concentrate on what has been achieved rather than focus on the discrepancy between their high standards and beliefs about being unable to achieve (Lo \& Abbott, 2013; Stoeber \& Otto, 2006). Positive psychological outcomes such as high life satisfaction (Park \& Jeong, 2015) and high academic performance (Rice, Lopez, \& Richardson, 2013) have been associated with adaptive perfectionism. These findings highlight that students with specific personality traits may possess cognitive biases that influence whether they perceive situations as stressful, supporting Spielberger and Vagg's (1995) theory.

\subsection{Coping Styles and Test Anxiety}

Spielberger and Vagg (1995) also postulated that after individuals appraise a testing situation as stressful, they employ coping strategies to manage their level of test anxiety. There has been a dearth of research examining multiple coping strategies as mediating mechanisms to explain why individuals with specific personality traits experience different test anxiety levels (Arana \& Furlan, 2016; Klibert et al., 2014; Park, Heppner, \& Lee, 2010). Weiner and Carton (2012) examined whether an overall coping style could explain the relationship between maladaptive perfectionism and test anxiety. An avoidant emotionfocused coping style (comprising coping strategies avoiding the stressor) was found to partially mediate the relationship between maladaptive perfectionism and high test anxiety, suggesting that strategies that comprise other coping styles may also explain this relationship. However, further research has revealed inconsistent findings regarding whether multiple coping styles act as mediating mechanisms (Klibert et al., 2014; Park et al., 2010).

The second proposal of Spielberger and Vagg's (1995) theory is based on Lazarus and Folkman's (1984) theory of stress and coping, suggesting individuals employ coping strategies to manage stress levels. Lazarus and Folkman (1984) postulated that the coping strategies used to manage stressors can form an overall coping style, a dominant coping 
approach across life situations. There are two main coping styles: problem-focused coping and emotion-focused coping (Lazarus \& Folkman, 1984). A problem-focused coping style involves engaging in behaviours to overcome the problem causing distress (e.g., devising a plan to study for a stressful exam) whereas emotion-focused coping is an attempt to regulate emotions that are evoked by the stressful event. An active emotion-focused coping style is an adaptive emotion-regulation strategy, comprised of coping strategies such as positive reframing. In contrast, an avoidant emotion-focused coping style is an attempt to avoid the stressor, including denial and behavioural disengagement (Folkman, 2013; Lazarus \& Folkman, 1984). There is no particular successful coping style; however, some coping styles may be more helpful when managing stress. For example, a problem-focused coping style may be considered more adaptive when faced with a stressful upcoming exam compared to an emotion-focused coping style, which may be considered unhelpful in this context.

Endler and Parker (1990) proposed that individuals are able to utilise strategies comprising other coping styles to manage a stressful situation, despite having an overall dominant coping style. For example, individuals may have a dominant active emotionfocused coping style; however, they may make a schedule and seek social support when preparing for an upcoming exam. Despite this proposal, there has been little research examining multiple coping styles of Australian undergraduate students and inconsistent findings regarding specific coping styles that may mediate the relationships between adaptive/maladaptive perfectionism and test anxiety.

Larijani and Besharat (2010) recruited 378 undergraduate students using the Tehran Coping Styles Scale, a Farsi version of the COPE scale (TCSS; Carver, Scheier, \& Weintraub, 1989), to examine how coping styles explain the relationships between perfectionism types and perceived stress. Maladaptive perfectionism was significantly associated with high levels of perceived stress and an avoidant emotion-focused coping style. 
In contrast, adaptive perfectionism was associated with low levels of perceived stress and with problem-focused and active emotion-focused coping styles. Arana and Furlan (2016) gave the Coping with Pre-Exam Anxiety and Uncertainty - Argentinian version (COPEAUA; Heredia, Piemontesi, Furlan, \& Pérez, 2008) to 277 students to examine the relationships between perfectionism, coping, and test anxiety. In contrast to Larijani and Besharat (2010), it was found that problem-focused coping explained the relationships between adaptive/maladaptive perfectionism and test anxiety. The inconsistency in findings regarding coping styles may reflect methodological issues apparent in both studies including social desirability bias, sample bias, and the influence of extraneous variables.

\subsection{Purpose of the Current Study}

Based on prior research and Spielberger and Vagg's (1995) theory, the current study sought to examine which coping strategies first year university students use to manage their test anxiety. This study aimed to quantify the strength of Lazarus and Folkman's three coping styles (i.e., problem-focused, active emotion-focused, and avoidant emotion-focused) as mediating mechanisms of the relationships between adaptive/maladaptive perfectionism and test anxiety. The current study intended to address methodological issues apparent in previous research and test the second proposal of Spielberger and Vagg's (1995) theory within a first-year Australian undergraduate student population.

To control for social desirability bias, short Form C of the Marlowe-Crowne Social Desirability Scale (MC-SDS; Crowne \& Marlowe, 1960) was administered to assess whether participants were responding truthfully. Participants were also instructed to rate (on a 5-point scale) the extent to which they believed that speaking English as a second language, having a disability, or impaired vision impacted their daily life. Individuals from linguistically diverse backgrounds may experience high test anxiety, believing failure strengthens negative group stereotypes (Salend, 2011); while students with disabilities have increased test anxiety 
associated with academic and organisational difficulties (Salend). Additionally, severe vision problems are also associated with high test anxiety due to difficulty reading (Datta, 2014). If participants indicated that these characteristics impaired them To a Great Extent (i.e., rating of 5), their data was excluded from the proposed analyses.

Many studies have found that perfectionism is associated with anxiety and depression (Arana \& Furlan, 2016; DiBartolo et al., 2008; Lo \& Abbott, 2013; Tran \& Rimes, 2017). Accordingly, participants whose scores corresponded to 'extremely severe' on the Depression Anxiety Stress Scale-21 (DASS-21) were removed to avoid potential confounding effects. Finally, previous research has not controlled for the influence of extraneous variables [females experienced more test anxiety than males (Lowe, 2014)]. The current study controlled for the effects of social desirability and gender.

\subsection{Aims and Hypotheses of the Current Study}

In line with Spielberger and Vagg's (1995) transactional process model of test anxiety and prior research, two hypotheses were postulated:

I. A problem-focused coping style would be the strongest mediator of the relationship between adaptive perfectionism and test anxiety.

II. An avoidant emotion-focused coping style would be the strongest mediator of the relationship between maladaptive perfectionism and test anxiety.

\section{Method}

\subsection{Participants and Procedure}

The initial dataset of 222 participants, consistent with the criteria for the current study, was reduced to 148 participants: 43 had missing data on key variables; 3 were not first year university students; 11 were not completing an undergraduate degree; 12 obtained extreme scores on the depression, anxiety and stress scale; 3 had not given approval for their data to be used in the study; and 2 indicated that having a disability, speaking English as a second 
language, or having poor vision greatly impaired their daily life. This stringent approach was used to reduce potential confounds.

The age of participants ranged from 18 to $56(M=22.84, S D=7.60)$, with $74.30 \%$ of the sample being female. The majority of the sample studied at one of two south-east Queensland universities (total: $93.90 \%$ ), with $48.60 \%$ of participants studying Social Science and Arts degrees, 30.40\% Business degrees, 15.50\% Health Science and Medicine degrees, and 5.40\% Law degrees. Before commencement, the study gained ethical approval from the universities' Human Research Ethics Committees. Participants were recruited via convenience sampling avenues including Facebook and universities. Students at one of the universities gained credit for participation and students from other universities were offered the opportunity to enter a prize draw to win a $\$ 20$ shopping voucher.

\subsection{Measures}

\subsubsection{Demographic Questionnaire}

Participants were asked questions regarding age; gender (male or female); highest level of education; current university; university year; and also, whether they had a visual impairment, disability, or English was their second language. Participants were asked to rate, on a 5-point Likert-type scale, to what extent they believed their impairments hindered their daily life.

\subsubsection{Depression Anxiety Stress Scale-21 (DASS-21; Lovibond \& Lovibond, 1995)}

The DASS is a 21-item self-report measure comprised of three subscales, which are designed to screen for levels of depression (DASS-D, 7-items), anxiety (DASS-A, 7-items), and stress (DASS-S, 7-items) in the general population. Respondents were asked to indicate how much each statement applied to them over the past week on a 4-point Likert-type scale $(0=$ Did Not Apply to Me at All to $3=$ Applied to Me Very Much or Most of the Time $)$. Items corresponding to each subscale can be added, with higher scores indicating greater levels of 
psychological distress. Consistent with existing literature, internal consistencies in the current study were good for DASS-D $(\alpha=.85)$ and DASS-S $(\alpha=.84)$ subscales and adequate for the DASS-A subscale; $\alpha=.71$ (Mahmoud, Hall, \& Staten, 2010).

2.2.3 Almost Perfect Scale - Revised (APS-R; Slaney, Mobley, Trippi, Ashby, \& Johnson, 1996)

The APS-R is a 23-item self-report measure, designed to assess perfectionism in the general population. Individuals were asked to rate their attitudes towards themselves, their performance, and towards others on a 7-point Likert-type scale $(1=$ Strongly Disagree to $7=$ Strongly Agree). The APS-R is comprised of three subscales of perfectionism; Standards (7items; high personal standards), Order (4-items; participants' organisation and need for order), and Discrepancy (12-items; distress caused by the discrepancy between performance and standards for expected performance). Items corresponding to each subscale can be added to yield three scores, with higher scores indicating greater manifestations on each of the respective subscales. Slaney et al. (1996) proposed that the Standards and Discrepancy subscales comprise dimensions of perfectionism. The Standards subscale was designed to be a continuous measure of high standards (adaptive perfectionism) and the Discrepancy subscale was designed to be a continuous measure of distress (maladaptive perfectionism). Cronbach's alpha was excellent for the APS-R $(\alpha=.91)$ and for the Standards $(\alpha=.88)$ and Discrepancy $(\alpha=.96)$ subscales in this study.

\subsubsection{Brief COPE Inventory (Brief COPE; Carver, 1997)}

The brief COPE is an abbreviated 28-item version of the COPE inventory, which is a 60-item self-report measure. Individuals are asked to rate items on a 4-point Likert-type scale ( 1 = I haven't been doing this at all to $4=$ I've been doing this a lot $)$. The inventory consists of 14 subscales representing different types of coping strategies. To assess Lazarus and Folkman's (1984) coping styles as mediating mechanisms, the current study formed coping 
styles in accordance with exploratory factor analyses conducted in previous studies (Litman, 2006; Ryan, 2013; Wu et al., 2017). Total scores for coping styles were calculated by adding respective subscales. Total scores ranged from 6 to 24 for problem-focused coping, 10 to 40 for active emotion-focused coping, and from 12 to 48 for avoidant emotion-focused coping. Internal consistencies ranged from adequate to good for problem-focused coping $(\alpha=.84)$, active emotion-focused coping ( $\alpha=.73$ ), and avoidant emotion-focused coping $(\alpha=.84)$.

\subsubsection{Test Anxiety Inventory (TAI; Spielberger, 1980)}

The TAI is a 20-item self-report measure, which asks respondents to rate on a 4-point Likert-type scale $(1=$ Almost Never to $4=$ Almost Always $)$ how they generally feel before, during, and after examinations. The inventory comprised of two subscales, Worry (TAI-W; 8-items; assessing concerns about failing a test) and Emotionality (TAI-E; 8-items; assessing feelings of being tense and uneasy when taking a test), which measure individual differences in anxiety during test situations. Four additional items load onto both subscales and contribute to the total test anxiety score. Subscale scores range from 8 to 32 and total scores range from 20 to 80, with higher scores indicating higher levels of test anxiety. In this study, total test anxiety scores were used to compare test anxiety experienced. Consistent with previous research, the current study found excellent internal consistency for the TAI scale; $\alpha$ $=.96$ (Ware, Galassi, \& Dew, 1990).

2.2.6 Marlowe-Crowne Social Desirability Scale (MC-SDS; Crowne \& Marlowe, 1960)

To control for social desirability, short Form C (Reynolds, 1982) was used. The measure is comprised of 13 true-false statements intended to detect dishonest responding with higher scores indicating a greater likelihood of impression management. The current study found that short form $\mathrm{C}$ had adequate internal consistency $(\alpha=.72)$, consistent with findings from Ray (1984). 


\subsection{Design}

\subsubsection{Bootstrapping Analyses}

The Hayes (2013) bootstrapping method can distinguish between five types of multiple mediation as it includes multiple mediators in one analysis (Zhao, Lynch, \& Chen, 2010). The use of bootstrapping allows for the creation of confidence intervals for the size of the indirect effect, path $a b$ (Preacher \& Hayes, 2008). If the confidence interval of the indirect effect does not cross zero, there is evidence for mediation from estimating the size of the indirect effect itself (Hayes, 2013; Zhao et al., 2010). The Preacher and Hayes' (2008) process was used to assess multiple coping styles as mediators.

\section{Results}

\subsection{Preliminary Analyses}

Initially, an a priori G*Power 3.10 analysis (Faul, Erdfelder, Lang, \& Buchner, 2007) indicated that the final sample of 148 was sufficient to detect a medium effect size of .15 . Table 1 displays the means, standard deviations and Pearson bivariate correlations between each of the study's key variables. Bivariate correlations between key study variables indicated that the assumption of multicollinearity $(<.90)$ was met and the proposed analyses could be conducted (Cohen, Cohen, West, \& Aiken, 2003; Tabachnick \& Fidell, 2014). As shown in Table 1, discrepancy was positively related to avoidant emotion-focused coping and test anxiety, and avoidant emotion-focused coping was positively associated with test anxiety. These correlations supported entry of avoidant emotion-focused coping as a mediator of the relationship between discrepancy (maladaptive perfectionism) and test anxiety.

Standards (adaptive perfectionism) had a positive association with problem-focused coping. However, associations between other study variables failed to reach significance. This was not a cause for concern as Hayes (2013) specified that if the bivariate correlations between the predictor, mediator variables, and the outcome variable are not significant, it is 
still possible that the product of path $a$ and $b$ in a mediated model can be significant after controlling for covariates (social desirability and gender). In such cases, the indirect effect can still be interpreted (Hayes, 2013). Thus, all coping styles were entered into two mediation models.

Table 1.

Means, Standard Deviations and Pearson Bivariate Correlations between Key Study Variables $(N=148)$.

\begin{tabular}{llllllll}
\hline Variable & $M$ & $S D$ & 1. & 2. & 3. & 4. & 5.
\end{tabular}

1. Discrepancy

2. Standards

3. Problem-focused

Coping

4. Active Emotion-focused

Coping

5. Avoidant Emotionfocused Coping

6. Test Anxiety

$49.78 \quad 17.50$

$\begin{array}{lll}39.76 & 7.03 \quad .16\end{array}$

15.18

4.19

$-.16$

$.21^{*}$

6.

.


$=-.31, p<.001$. The covariates, gender and social desirability, were not significantly correlated; $r_{p b}=.09, p=.266$. No significant interaction was found between the independent variable (type of perfectionism) and covariates (gender and social desirability), $F(3,140)=$ $0.30, p=.833$. Accordingly, social desirability and gender were included as covariates.

\subsection{Multiple Mediations}

Multiple mediations were carried out in PROCESS to assess the relative explanatory power of each coping style in explaining the relationships between adaptive/maladaptive perfectionism and test anxiety. Consistent with previous researchers, the APS-R subscale of interest was entered as the predictor variable while the second APS-R subscale was entered as a covariate (Gnilka, Ashby, \& Noble, 2012; Rice \& Ashby, 2007). Social desirability and gender were entered as covariates in both multiple mediations. Estimates of the indirect effect, direct effect and total effect were based on 10,000 bootstrapped samples. An alpha level of .05 was used to determine statistical significance for each of the paths in the mediation models.

\subsubsection{Adaptive Perfectionism}

The overall model accounted for $26 \%$ of variance in test anxiety and was significant; $R^{2}=.26, F(4,143)=15.73, p<.001$. Additionally, the covariates of gender and discrepancy accounted for significant variance in the overall model; $\beta=-.21, S E=.06, p=.001$ and $\beta=$ $.42, S E=.07, p<.001$ respectively. Figure 1 displays the unmediated and mediated model for adaptive perfectionism with covariates excluded. As shown in the unmediated model, the path between adaptive perfectionism and test anxiety (path $c$, total effect) was not significant.

\subsubsection{Problem-focused coping mediator}

Figure 1 indicates the link between adaptive perfectionism and problem-focused coping (path $a$ ) was significant and positive, such that higher scores on standards corresponded to higher scores on problem-focused coping. Conversely, the relationship 
between problem-focused coping and test anxiety (path $b$ ) was not significant. The overall indirect effect (product of path $a$ and path $b$ ) of the relationship between adaptive perfectionism and test anxiety through problem-focused coping was not significant; $\beta=-.00$, $S E=.03$, boot $95 \%$ CI $[-0.06,0.05]$. Thus, the indirect effect of problem-focused coping on the relationship between adaptive perfectionism and test anxiety was not significant.

\subsubsection{Active emotion-focused coping mediator}

Figure 1 shows that adaptive perfectionism did not significantly predict active emotion-focused coping (path $a$ ) and active emotion-focused coping did not significantly predict test anxiety (path $b$ ). Therefore, the indirect effect from adaptive perfectionism to test anxiety through active emotion-focused coping was nonsignificant and mediation was not supported for active emotion-focused coping; $\beta=-.00, S E=.01$, boot 95\% CI [-0.04, 0.01$]$.

\subsubsection{Avoidant emotion-focused coping mediator}

Referring to Figure 1, the relationship between adaptive perfectionism and avoidant emotion-focused coping (path $a$ ) was significant and negative, with higher scores on standards associated with lower avoidant emotion-focused coping scores. In contrast, the relationship between avoidant emotion-focused coping and test anxiety (path $b$ ) was significant and positive, such that higher scores on avoidant emotion-focused coping corresponded to higher test anxiety scores. The combined indirect effect between adaptive perfectionism and test anxiety through avoidant emotion-focused coping was significant such that adaptive perfectionism worked through avoidant emotion-focused coping to predict lower scores on test anxiety; $\beta=-.06, S E=.03$, boot $95 \%$ CI $[-0.14,-0.01]$.

According to Hayes (2013), the total effect (path $c$ ) does not need to be a pre-requisite for mediation as indirect-only mediation can occur where the relationship between the predictor and the outcome variable occurs exclusively through the mediator. The results from the current mediation model indicate indirect-only mediation where avoidant emotion- 
focused coping fully mediated the relationship between adaptive perfectionism and test anxiety (Zhao et al., 2010). Therefore, the first hypothesis was not supported as problemfocused coping was not the strongest mediator of the relationship between adaptive perfectionism and test anxiety.

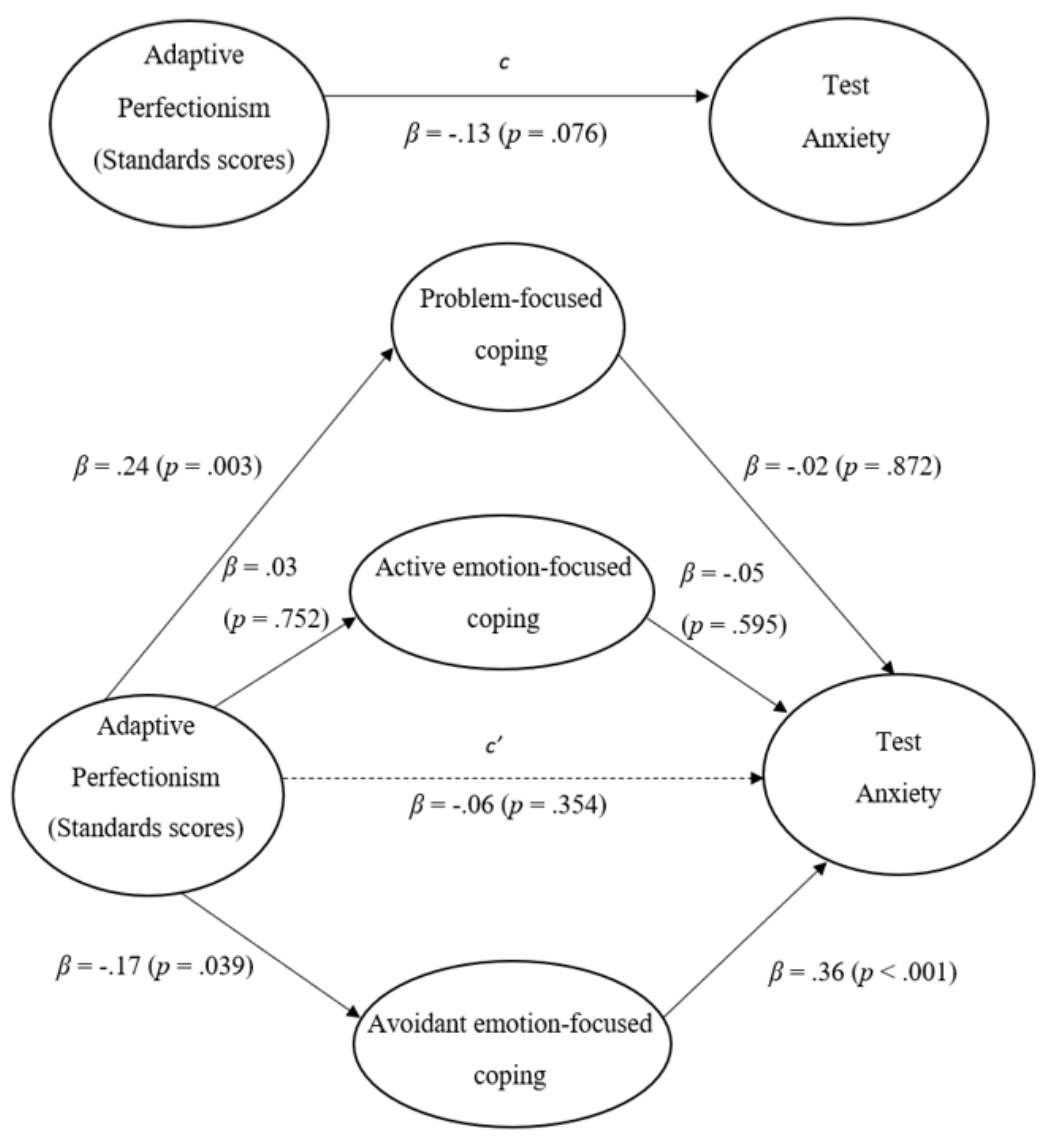

Figure 1. Unmediated and mediated models for adaptive perfectionism. Standardised beta coefficients reported.

\subsubsection{Maladaptive Perfectionism}

The overall model accounted for $26 \%$ of variance in test anxiety and was significant; $R^{2}=.26, F(4,143)=15.73, p<.001$. Additionally, gender was the only covariate that accounted for significant variance in the overall model; $\beta=-.21, S E=.06, p=.001$. Figure 2 displays the unmediated and mediated model for maladaptive perfectionism with covariates excluded. As seen in the unmediated model, the path between maladaptive perfectionism and 
test anxiety (path $c$ ) was significant and positive, suggesting that higher discrepancy scores predicted higher levels of test anxiety.

\subsubsection{Problem-focused coping mediator}

Figure 2 indicates the link between maladaptive perfectionism and problem-focused coping (path $a$ ) was significant and negative, such that higher scores on discrepancy corresponded to lower scores on problem-focused coping. In contrast, the relationship between problem-focused coping and test anxiety (path $b$ ) was not significant. The overall indirect effect indicated that the relationship between maladaptive perfectionism and test anxiety through problem-focused coping was not significant; $\beta=.00, S E=.03$, boot $95 \% \mathrm{CI}$ $[-0.05,0.06]$. Thus, problem-focused coping was not a significant mediator of the relationship between maladaptive perfectionism and test anxiety.

\subsubsection{Active emotion-focused coping mediator}

Figure 2 shows that maladaptive perfectionism did not significantly predict active emotion-focused coping (path $a$ ) and active emotion-focused coping did not significantly predict test anxiety (path $b$ ). Thus, the indirect effect from maladaptive perfectionism to test anxiety through active emotion-focused coping was nonsignificant, therefore mediation was not supported for active emotion-focused coping; $\beta=.00, S E=.01$, boot $95 \%$ CI [-0.01, $0.05]$.

\subsubsection{Avoidant emotion-focused coping mediator}

The relationship between maladaptive perfectionism and avoidant emotion-focused coping was significant and positive, with higher scores on discrepancy associated with higher scores on avoidant emotion-focused coping. Additionally, the relationship between avoidant emotion-focused coping and test anxiety was significant and positive, such that higher scores on avoidant emotion-focused coping corresponded to higher test anxiety scores. The indirect effect from maladaptive perfectionism to test anxiety through avoidant emotion-focused 
coping was significant such that maladaptive perfectionism worked through avoidant emotion-focused coping to predict higher scores on test anxiety; $\beta=.15, S E=.04$, boot $95 \%$ CI $[0.07,0.24]$.

In accordance with Zhao et al.'s (2010) complementary mediation, both the direct effect (path $c^{\prime}$, in Figure 2) and the indirect effect through avoidant emotion-focused coping were positive and significantly related to test anxiety. Therefore, hypothesis two was supported as avoidant emotion-focused coping was the strongest mediator of the relationship between maladaptive perfectionism and high test anxiety scores.

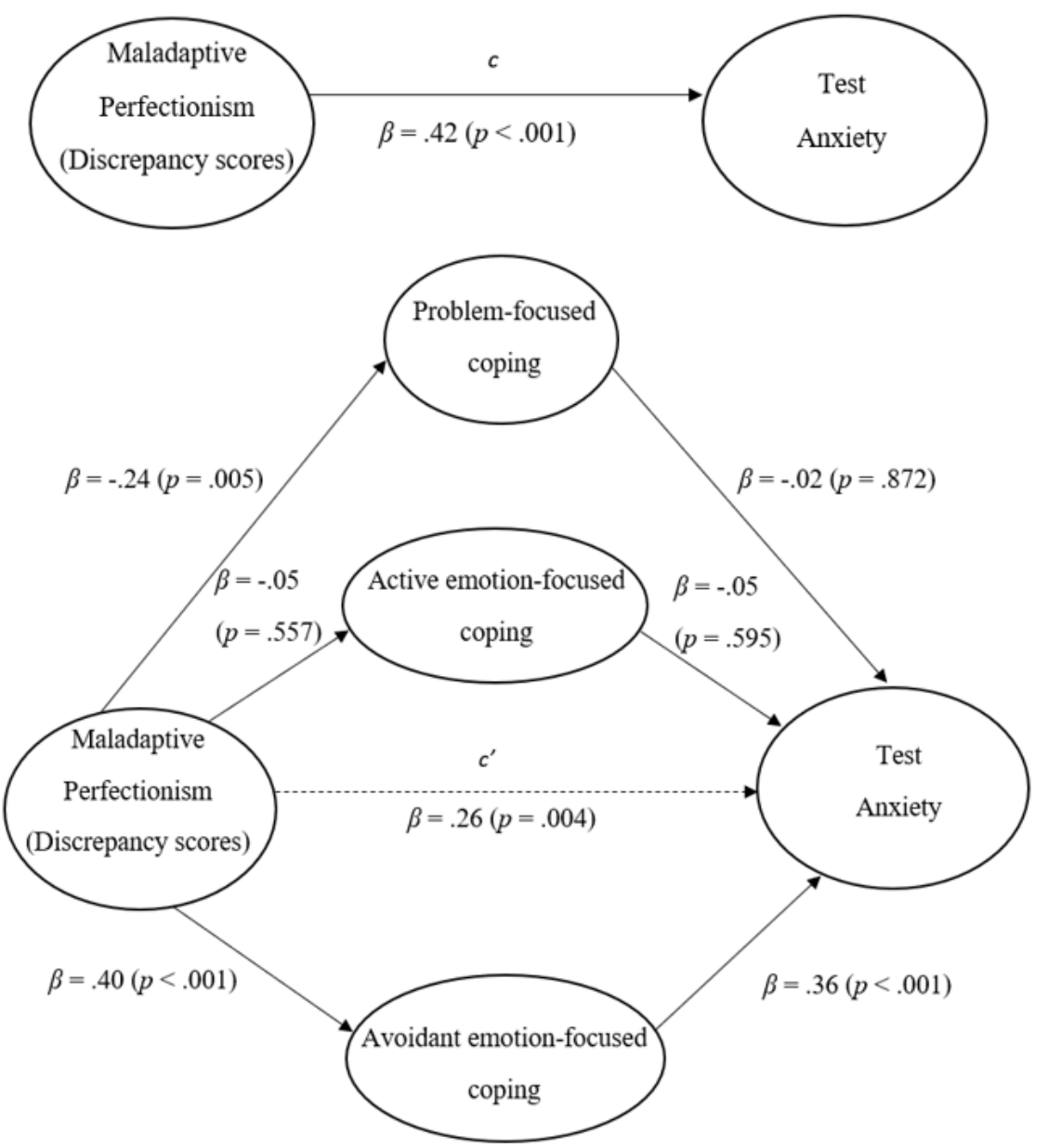

Figure 2. Unmediated and mediated models for maladaptive perfectionism. Standardised beta coefficients reported. 


\section{Discussion}

The current study identified a notable gap in the literature concerning how personality traits and coping strategies influence the level of test anxiety experienced, which may in turn affect attrition rates in first year university students. There have been inconsistent findings regarding how coping styles explain the relationships between adaptive perfectionism and low test anxiety and between maladaptive perfectionism and high test anxiety (Gnilka et al., 2012; Weiner \& Carton, 2012). In light of this research, the current study examined further the relationships between perfectionism, Lazarus and Folkman's coping styles, and test anxiety.

The first multiple mediation between adaptive perfectionism, coping styles, and test anxiety revealed that problem-focused coping was not a significant mediator; therefore, hypothesis one was not supported. Results showed that adaptive perfectionism worked though avoidant emotion-focused coping to predict low test anxiety. Low test anxiety in students with adaptive perfectionism may be the result of adaptive perfectionists using less avoidant emotion-focused coping (including self-distraction, self-blame, behavioural disengagement, substance abuse, denial, and venting subscales) when managing exam anxiety. Contrasting previous research (Arana \& Furlan, 2016; Larijani \& Besharat, 2010), this finding suggests that adaptive perfectionists may appraise upcoming tests in a positive light as they use less avoidant emotion-focused coping to manage test anxiety, consistent with Spielberger and Vagg's (1995) model. This result may be due to methodological issues apparent in previous research being accounted for in the current study (previous research included individuals with comorbid anxiety and test anxiety, potentially confounding findings).

Regarding the second hypothesis, the second mediation model revealed that avoidant emotion-focused coping was the only significant mediating mechanism such that maladaptive 
perfectionism worked through avoidant emotion-focused coping to predict high test anxiety. The current findings suggest that maladaptive perfectionists are more likely to use an avoidant emotion-focused coping style when managing exam stress. This result supported hypothesis two and Spielberger and Vagg's (1995) theory of test anxiety. It is important to note that gender was a significant covariate in both multiple mediation models. Consistent with Lowe (2014), females reported higher levels of test anxiety than did males. It seems that female first year university students may require more information and support to reduce exam stress than do their male counterparts.

\subsection{Evaluation of the Study and Future Directions}

Understanding how personality traits shape individuals' appraisals of situations and influence coping strategies in managing stressful situations provides a basis for universities to support students in reducing exam stress. However, there are some limitations. Firstly, social media was used to recruit participants and valid results rely on accurate responses. Short form $\mathrm{C}$ of the MC-SDS was administered to mitigate this risk as much as possible. Secondly, though our sample size was reasonable and several aspects were controlled, this study can be biased in unexpected ways (age differences, socioeconomic impacts, nationality impacts, and different university program impacts). Further studies with larger samples and/or more targeted groupings would help confirm the findings from the sample reported in this paper.

Based on the current findings, it may be beneficial for future studies to extend this theoretical research and conduct experiments whereby, for example, first year undergraduate university students are taught to reduce their reliance on strategies associated with an avoidant emotionfocused coping style (e.g., self-distraction, self-blame, denial).

\subsection{Conclusion}

The current study aimed to extend previous research by clarifying the roles of coping styles in explaining the relationships between adaptive/maladaptive perfectionism and test 
anxiety. Overall, the findings provide evidence supporting Spielberger and Vagg's (1995) model by showing that coping mechanisms are able to explain the relationship between personality traits and test anxiety experienced in first year university students.

\section{Acknowledgements}

There were no funding support arrangements made in regards to the findings reported. 


\section{References}

Abdollahi, A., Carlbring, P., Vaez, E., \& Ghahfarokhi, S. A. (2016). Perfectionism and test anxiety among high-school students: The moderating role of academic hardiness. Current Psychology, 1, 1-8. doi: 10.1007/s12144-016-9550-z.

Arana, F. G., \& Furlan, L. (2016). Groups of perfectionists, test anxiety, and pre-exam coping in Argentine students. Personality and Individual Differences, 90, 169-173. doi: 10.1016/j.paid.2015.11.001.

Bassols, A. M., Okabayashi, L. S., Silva, A. B. D., Carneiro, B. B., Feijó, F., Guimarães, G. C., ... \& Eizirik, C. L. (2014). First-and last-year medical students: Is there a difference in the prevalence and intensity of anxiety and depressive symptoms? Revista Brasileira de Psiquiatria, 36, 233-240. doi: 10.1590/1516-4446-2013-1183.

Brinkworth, R., McCann, B., Matthews, C., \& Nordström, K. (2009). First year expectations and experiences: Student and teacher perspectives. Higher Education, 58, 157-173. doi: 10.1007/s10734-008-9188-3.

Carver, C. S. (1997). You want to measure coping but your protocol's too long: Consider the Brief COPE. International Journal of Behavioral Medicine, 4, 92-100. doi: 10.1207/s15327558ijbm0401_6.

Carver, C. S., Scheier, M. F., \& Weintraub, J. K. (1989). Assessing coping strategies: A theoretically based approach. Journal of Personality and Social Psychology, 56, 267283. doi: 10.1037/0022-3514.56.2.267.

Castro, J., Soares, M. J., Pereira, A. T., \& Macedo, A. (2017). Perfectionism and negative/positive affect associations: The role of cognitive emotion regulation and perceived distress/coping. Trends in Psychiatry and Psychotherapy, 39, 77-87. doi: 10.1590/2237-6089-2016-0042. 
Chae, M. S. (2015). The mediating effects of test anxiety on the relationship between socially-prescribed perfectionism and academic burnout of female college students in a dental hygiene department. Journal of Korean Academy of Oral Health, 39, 295302. doi: 10.11149/jkaoh.2015.39.4.295.

Cohen, J., Cohen, P., West, S.G., \& Aiken, L.S. (2003). Applied Multiple Regression/Correlation Analysis for the behavioral sciences, (3rd ed.). New York, NY: Routledge.

Crowne, D. P., \& Marlowe, D. (1960). A new scale of social desirability independent of psychopathology. Journal of Consulting Psychology, 24, 349-355. doi: $10.1037 / \mathrm{h} 0047358$.

Datta, P. (2014). Test anxiety research: Students with vision impairments and students with mild Intellectual Disabilities. International Journal of Special Education, 27, 68-74. Retrieved from https://files.eric.ed.gov/fulltext/EJ1029008.pdf.

Department of Education and Training. (2017). Improving retention, completion and success in higher education [PDF file]. Retrieved from https://docs.education.gov.au.

DiBartolo, P. M., Li, C. Y., \& Frost, R. O. (2008). How do the dimensions of perfectionism relate to mental health? Cognitive Therapy and Research, 32, 401-417. doi: $10.1007 / \mathrm{s} 10608-007-9157-7$.

Duty, S. M., Christian, L., Loftus, J., \& Zappi, V. (2016). Is cognitive test-taking anxiety associated with academic performance among nursing students? Nurse Educator, 41, 70-74. doi: 10.1097/NNE.0000000000000208.

Endler, N. S., \& Parker, J. D. (1990). Multidimensional assessment of coping: A critical evaluation. Journal of Personality and Social Psychology, 58, 844-854. doi: $10.1037 / / 0022-3514.58 .5 .844$. 
Faul, F., Erdfelder, E., Lang, A-G., \& Buchner, A. (2007). G*Power 3: A flexible statistical power analysis program for the social, behavioral, and biomedical sciences. Behavior Research Methods, 39, 175-191. doi: 10.3758/BF03193146.

Folkman, S. (2013). Stress: Appraisal and coping. New York, NY: Springer.

Gnilka, P. B., Ashby, J. S., \& Noble, C. M. (2012). Multidimensional perfectionism and anxiety: Differences among individuals with perfectionism and tests of a copingmediation model. Journal of Counseling \& Development, 90, 427-436.doi: 10.1002/j.1556-6676.2012.00054.x.

Hamachek, D. (1978). Psychodynamics of normal and neurotic perfectionism. Psychology, 15, 27-33. Retrieved from http://psycnet.apa.org/psycinfo/1979-08598-001. Hayes, A.F. (2013). Introduction to Mediation, Moderation, and Conditional Process Analysis: A regression based approach. New York, NY: The Guilford Press.

Heredia, D., Piemontesi, S., Furlan, L., \& Pérez, E. (2008). Adaptación de una escala de afrontamiento de la ansiedad e incertidumbre pre-examen para estudiantes universitarios argentinos. Avaliação psicológica, 7, 1-9. Retrieved from http://www.redalyc.org/html/3350/335027183003.

Hunt, J., \& Eisenberg, D. (2010). Mental health problems and help-seeking behavior among college students. Journal of Adolescent Health, 46, 3-10. doi: 10.1016/j.jadohealth.2009.08.008.

Karabenick, S. A., \& Zusho, A. (2015). Examining approaches to research on self-regulated learning: Conceptual and methodological considerations. Metacognition and Learning, 10, 151-163. doi: 10.1007/s11409-015-9137-3. 
Klibert, J., Lamis, D. A., Collins, W., Smalley, K. B., Warren, J. C., Yancey, C. T., \& Winterowd, C. (2014). Resilience mediates the relations between perfectionism and college student distress. Journal of Counseling \& Development, 92, 75-82. doi: 10.1002/j.1556-6676.2014.00132.x.

Larijani, R., \& Besharat, M. A. (2010). Perfectionism and coping styles with stress. Procedia-Social and Behavioral Sciences, 5, 623-627. doi: 10.1016/j.sbspro.2010.07.154.

Lazarus, R. S., \& Folkman, S. (1984). Stress, appraisal, and coping. New York, NY: Springer.

Litman, J. A. (2006). The COPE inventory: Dimensionality and relationships with approachand avoidance-motives and positive and negative traits. Personality and Individual Differences, 41, 273-284. doi: 10.1016/j.paid.2005.11.032.

Lo, A., \& Abbott, M. J. (2013). Review of the theoretical, empirical, and clinical status of adaptive and maladaptive perfectionism. Behaviour Change, 30, 96-116. doi: 10.1017/bec.2013.9.

Lovibond, S.H. \& Lovibond, P.F. (1995). Manual for the Depression Anxiety Stress Scales, $\left(2^{\text {nd }}\right.$. Ed.). Sydney, Australia: Psychology Foundation of Australia.

Lowe, P. A. (2014). Should test anxiety be measured differently for males and females? Examination of measurement bias across gender on measures of test anxiety for middle and high school, and college students. Journal of Psychoeducational Assessment, 33, 238-246. https://doi.org/10.1177/0734282914549428.

Mahmoud, J. S. R., Hall, L. A., \& Staten, R. (2010). The psychometric properties of the 21Item Depression Anxiety and Stress Scale (DASS-21) among a sample of young adults. Southern Online Journal of Nursing Research, 10, 21-34. Retrieved from http://www.resourcenter.net/images/snrs/files/sojnr_articles2/Vol10Num04Art02.pdf. 
Moate, R. M., Gnilka, P. B., West, E. M., \& Bruns, K. L. (2016). Stress and burnout among counselor educators: Differences between adaptive perfectionists, maladaptive perfectionists, and nonperfectionists. Journal of Counseling \& Development, 94, 161171. doi: $10.1002 /$ jcad.12073.

Moroz, M., \& Dunkley, D. M. (2015). Self-critical perfectionism and depressive symptoms: Low self-esteem and experiential avoidance as mediators. Personality and Individual Differences, 87, 174-179. doi: 10.1016/j.paid.2015.07.044.

Park, H. J., Heppner, P. P., \& Lee, D. G. (2010). Maladaptive coping and self-esteem as mediators between perfectionism and psychological distress. Personality and Individual Differences, 48, 469-474. doi: 10.1016/j.paid.2009.11.024.

Park, H. J., \& Jeong, D. Y. (2015). Psychological well-being, life satisfaction, and selfesteem among adaptive perfectionists, maladaptive perfectionists, and nonperfectionists. Personality and Individual Differences, 72, 165-170. doi: 10.1016/j.paid.2014.08.031.

Preacher, K. J., \& Hayes, A. F. (2008). Asymptotic and resampling strategies for assessing and comparing indirect effects in multiple mediator models. Behavior Research Methods, 40, 879-891. doi: 10.3758/brm.40.3.879.

Ray, J. J. (1984). The reliability of short social desirability scales. The Journal of Social Psychology, 123, 133-134. doi: 10.1080/00224545.1984.9924522.

Regehr, C., Glancy, D., \& Pitts, A. (2013). Interventions to reduce stress in university students: A review and meta-analysis. Journal of Affective Disorders, 148, 1-11. doi: 10.1016/j.jad.2012.11.026.

Reynolds, W.M. (1982). Development of reliable and valid short forms of the MarloweCrowne Social Desirability Scale. Journal of Clinical Psychology, 38, 119-125. doi: $10.1002 / 1097-4679$. 
Rice, K. G., \& Ashby, J. S. (2007). An efficient method for classifying perfectionists. Journal of Counseling Psychology, 54, 72-85. doi: 10.1037/0022-0167.54.1.72.

Rice, K. G., Lopez, F. G., \& Richardson, C. M. (2013). Perfectionism and performance among STEM students. Journal of Vocational Behavior, 82, 124-134. doi: 10.1016/j.jvb.2012.12.002.

Ryan, K. (2013). How problem focused and emotion focused coping affects college students' perceived stress and life satisfaction. (Honours in Psychology, Dublin Business School, Dublin, Ireland). Retrieved from http://hdl.handle.net/10788/1622.

Salend, S. J. (2011). Addressing test anxiety. Teaching Exceptional Children, 44, 58-68. doi: $10.1177 / 004005991104400206$.

Slaney, R. B., Mobley, M., Trippi, J., Ashby, J. S., \& Johnson, D. (1996). Almost Perfect Scale-Revised. Measurement and Evaluation in Counseling and Development, 34, 130-145. doi:10.1037/t02161-000.

Spielberger, C. D. (1980). Test Anxiety Inventory: Preliminary professional manual. Palo Alto, CA: Consulting Psychologist Press.

Spielberger, C. D., \& Vagg, P. R. (1995). Test anxiety: A transactional process model. Philadelphia, PA: Taylor \& Francis.

Stoeber, J., \& Otto, K. (2006). Positive conceptions of perfectionism: Approaches, evidence, challenges. Personality and Social Psychology Review, 10, 295-319. doi: 10.1207/s15327957pspr1004_2.

Tabachnick, B., \& Fidell, L. (2014). Using Multivariate Statistics, (6th ed.). Boston, MA: Pearson. 
Tran, L., \& Rimes, K. A. (2017). Unhealthy perfectionism, negative beliefs about emotions, emotional suppression, and depression in students: A mediational analysis. Personality and Individual Differences, 110, 144-147. doi: 10.1016/j.paid.2017.01.042.

Ware, W. B., Galassi, J. P., \& Dew, K. M. H. (1990). The Test Anxiety Inventory: A confirmatory factor analysis. Anxiety Research, 3, 205-212. doi: 10.1080/08917779008248753.

Weiner, B. A., \& Carton, J. S. (2012). Avoidance coping: A mediator of maladaptive perfectionism and test anxiety. Personality and Individual Differences, 52, 632-636. doi: 10.1016/j.paid.2011.12.009.

Wu, D., Wang, K., Wei, D., Chen, Q., Du, X., Yang, J., \& Qiu, J. (2017). Perfectionism mediated the relationship between brain structure variation and negative emotion in a nonclinical sample. Cognitive, Affective, \& Behavioral Neuroscience, 17, 211-223. doi: $10.3758 / \mathrm{s} 13415-016-0474-8$.

Zamira, H. D. (2016). Factors influencing test anxiety among university students. The European Journal of Social and Behavioural Sciences, 1, 2325-2334. doi: 10.15405/ejsbs.206.

Zhao, X., Lynch, J. G., \& Chen, Q. (2010). Reconsidering Baron and Kenny: Myths and truths about mediation analysis. Journal of Consumer Research, 37, 197-206. doi: $10.1086 / 651257$. 